\title{
Fretting Fatigue In-service Failure of X20CrMo13 Stainless Steel Turbine Blade
}

\author{
Cassius Olívio Figueiredo Terra Ruchert ${ }^{a}$, Márcio Corrêa de Carvalho ${ }^{\circledR}$ (†, \\ Marcos Fábio Verísimo Montezuma ${ }^{b}$ \\ ${ }^{a}$ Universidade de São Paulo, Departamento de Engenharia de Materiais, EEL, Lorena, SP, Brasil. \\ ${ }^{b}$ Universidade Federal do Ceará, Laboratório de Mecânica da Fratura e Fadiga - LAMEFF, \\ Fortaleza, CE, Brasil.
}

Received: April 19, 2021; Revised: June 13, 2021; Accepted: July 02, 2021.

The turbine blades play a crucial role in the efficiency of the steam turbines system, which can also lead to safety and economic implications in a catastrophic failure. The propagation of fatigue cracks is a relevant issue, especially if there are safety issues involving human life or the environment or significant economic losses. This work investigated the failure of a turbine blade of a $25 \mathrm{MW}$ cogeneration power plant. One found several deformation marks and debris in the primary crack origin at the blade's base. They were responsible for the fretting fatigue type wear. The blade material matches the composition of $\mathrm{X} 20 \mathrm{CrMo} 13$ steel; however, the hardness shows a higher average value

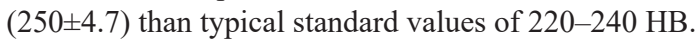

Keywords: Fretting; Fatigue; Wear; Cracks; Turbine blades.

\section{Introduction}

The turbine blades play a crucial role in the efficiency of the system in steam turbines, which can also lead to safety and economic implications in a catastrophic failure ${ }^{1}$. The propagation of fatigue cracks is a relevant issue, especially if there are safety issues involving human life or the environment or significant economic $\operatorname{losses}^{2}$. In general, several factors cause turbine blade failures. However, the factors that predominantly influence the blade's life are as follows: corrosion failure, fretting fatigue failure, and creep-fatigue failure ${ }^{3}$. Turbine failures can be associated with multiple component failure scenarios such as screws and blades ${ }^{4}$. The association of dynamic and chemical phenomena, such as fatigue and corrosion, respectively, have already been observed in in-service failures of martensitic 410 stainless steel turbine blades ${ }^{5}$. Intergranular fracture of a brittle nature resulting from the formation of oxides in the grain boundaries was observed in $304 \mathrm{H}$ austenitic stainless steels used to manufacture heat exchanger pipe connections ${ }^{6}$.

Fretting is the event in which contacting surfaces subjected to oscillatory relative movement suffer surface damage. Consequently, cracks form at the surface and result in fretting fatigue-related failures. The fretting fatigue phenomenon can split into different steps. The first step is to deteriorate the oxide layer on the surfaces. After the oxide layer degradation, micro welds or cold-welds form at the surface, increasing the measured coefficient of friction. Subsequent loading of the surfaces then causes these micro-welds to break, forming wear debris ${ }^{7}$. This wear debris can work as an abrasive medium and form a protective third body layer reducing wear ${ }^{8}$. Studies have shown that conventional heat treatments are able to increase the wear resistance of $\mathrm{H} 13$ tool

*e-mail: marciocorrea@usp.br steels ${ }^{9}$. Investigations of deformation processes followed by aging treatment demonstrated that heat treatment improves the mechanical strength and hardness of stainless steels ${ }^{10}$.

The coupling of the blade base with the disk is where fretting fatigue failures commonly occur ${ }^{11}$. Fretting occurs at the junction of contacting bodies due to oscillating force, which generates small relative displacement, and with small slip amplitude, wear effects are lower than fatigue effects, so crack growth is dominant, which is the case where fretting fatigue develops ${ }^{12,13}$ Fretting-fatigue damage in blade/disk interfaces has been identified as the cause of many unexpected disk and blade failures in gas turbine engines ${ }^{14}$.

Fretting wear occurs at the contact surface due to the alternating tangential stress. Surface peeling, delamination, and micro cracks are the main surface damage characteristics. The micro cracks will either grow into the main cracks directly, leading to fretting fatigue failure, or be eliminated by fretting wear ${ }^{15}$. The schematic of fretting fatigue damage and failure mechanism is shown in Figure 1.

After investigating a blade failure in a low-pressure turbine at a nuclear power plant, one concludes that low clearance between the blade and the disc caused a sliding movement. A crack in the blade started under fretting wear and propagated with high cycle fatigue by analyzing the blade fracture surface ${ }^{16}$.

The martensitic steel chromium $12 \%$, is the most applied among the many materials available for the manufacture of blades ${ }^{17}$, which combines excellent damping characteristics and toughness, strength, and corrosion resistance ${ }^{18}$.

To identify the probable causes that led to premature failure of the X20CrMo13 steel turbine blade of a $25 \mathrm{MW}$ cogeneration power plant, techniques of chemical analysis by optical emission spectroscopy, infrared absorption 


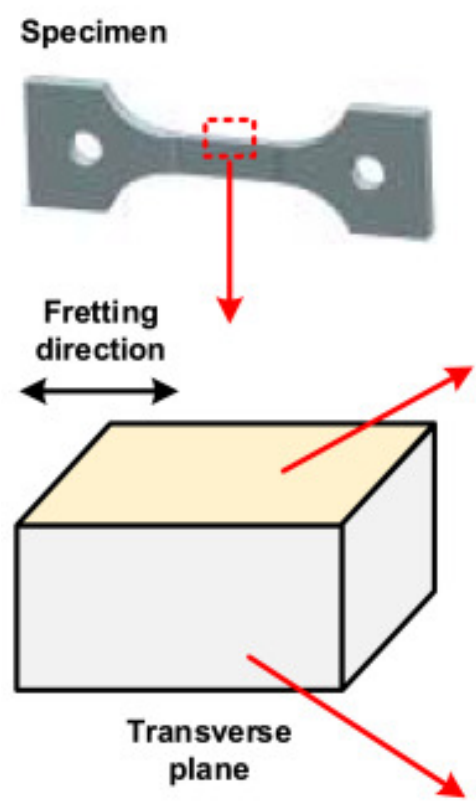

\section{Contact surface}

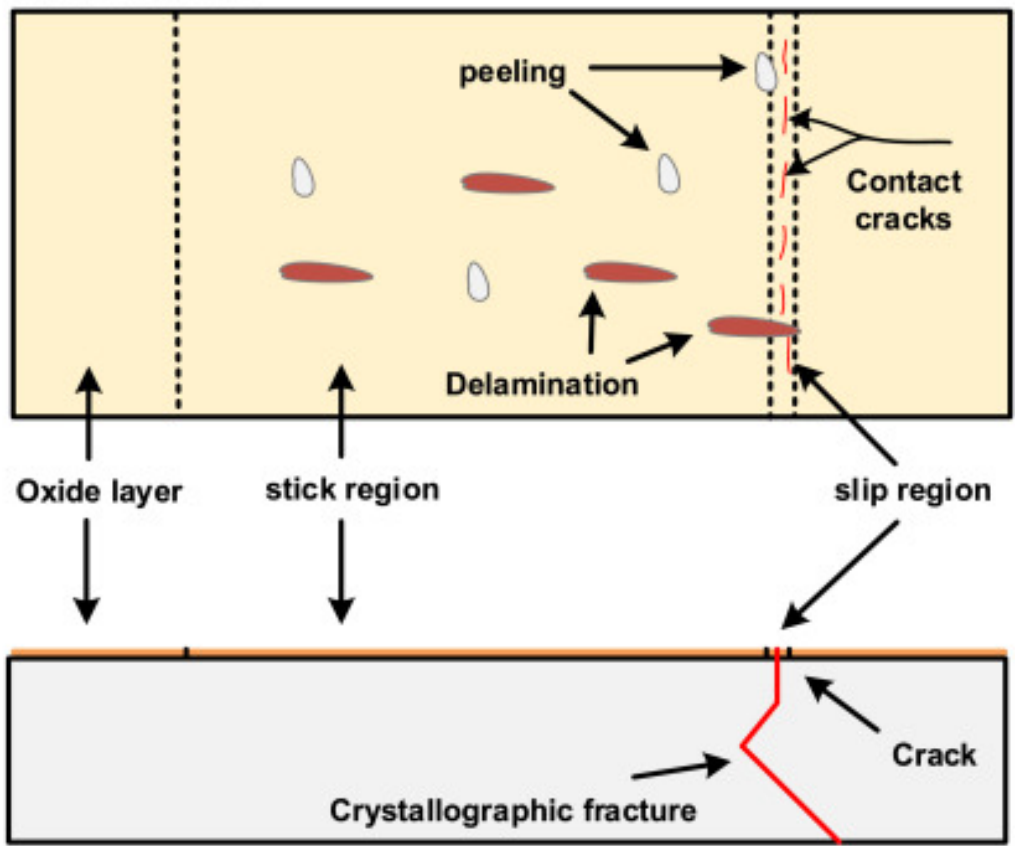

Figure 1. Schematic of fretting fatigue damage and failure mechanism ${ }^{10}$.

Table 1. Turbine operational parameters.

\begin{tabular}{|c|c|c|c|c|c|}
\hline Phase & 1 & 2 & 3 & 4 & Units \\
\hline Generator terminal power & 18 & 20.8 & 23.7 & 26.7 & MW \\
\hline Inlet steam pressure & 65 & 65 & 65 & 65 & $\mathrm{Kgf} / \mathrm{cm}^{2}$ \\
\hline Inlet steam temperature & 475 & 475 & 475 & 475 & ${ }^{\circ} \mathrm{C}$ \\
\hline Inlet steam flow rate & 119.9 & 125 & 140 & 155 & $\mathrm{t} / \mathrm{h}$ \\
\hline Outlet steam pressure & 1.5 & 1.5 & 1.5 & 1.5 & $\mathrm{Kgf} / \mathrm{cm}^{2}$ \\
\hline Turbine rotation rate & 6000 & 6000 & 6000 & 6000 & $\mathrm{rpm}$ \\
\hline Generator rotation rate & 1800 & 1800 & 1800 & 1800 & $\mathrm{rpm}$ \\
\hline Tolerance & 3 & 3 & 3 & 3 & $\%$ \\
\hline
\end{tabular}

spectroscopy, metallographic analysis by optical microscopy, and fractographic analysis by optical stereoscopy and microscopy, and scanning electron microscopy, and Brinnel hardness test.

\section{Experimental Procedure}

The turbine of a $25 \mathrm{MW}$ cogeneration power plant operates according the parameters shown in Table 1. The blade geometry and dimensions analyzed in this work is shown in Figure 2.

Figure $3 \mathrm{~A}$ shows the investigated parts represented by the numbers P1, P2, and P3. The P1 and P3 blade (2500h service exposed) mounted on the turbine rotor, adjacent to the failed blade (P1 before, and P3 after the P2 blade). The virgin blade (VB), without service, is shown in Figure 4, to compare the microstructure and surface finishes. The samples selected for the metallographic analysis took from the longitudinal section of the virgin's blade lamination direction and fractured blades. The samples were then ground and polished with diamond, alumina, and colloidal silica solutions, based on standardized sample preparation

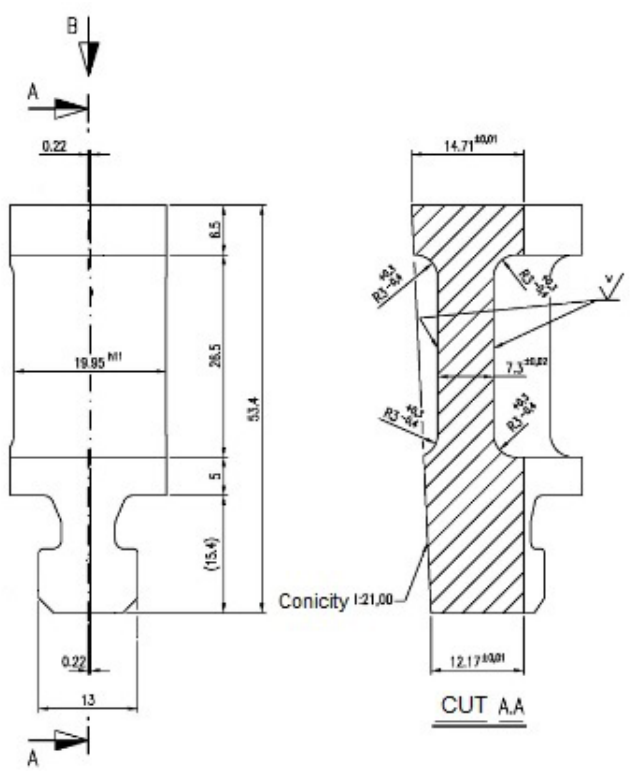

Figure 2. Geometry and dimensions $(\mathrm{mm})$ of the turbine blade. 
procedures for metallography in ASTM E3-11, Standard $^{19}$. Metallographic analyzes were performed with and without chemical etching. The chemical etching is doing with Villela's etchant. An etching was also carried out with the Picral etchant to reveal the austenitic grain size. Inclusions are classifying according to the "A" method of ASTM E45-18a, standard ${ }^{20}$. The fractographic sample was analyzed by scanning electron microscopy (SEM), after cleaning the oxides and fatty acids with an acid mixture solution on ultrasound. Optical images were taken with a Zeiss LAB.A1 optical microscope and a Zeiss Discovery V8 optical stereoscope. Chemical analyses were conducted with a Thermo Scientifics ARL 4560 optical emission spectrometer, and SEM images were taken by a field emission scanning electron microscope FEI F50, coupled with an energy dispersive spectrometer. Hardness measurements were performed on the surface (center of the cross-section) of the adjacent blade P1, see Figure 1, using a Testor2 Otto Wolpert-Werke hardness tester with a bearing of $2.5 \mathrm{~mm}$ in diameter under a load of $187.5 \mathrm{kgf}\left(\mathrm{P} / \mathrm{D}^{\wedge} 2=30\right)$.

\section{Results and Discussion}

The P2 blade failed in-service is the main object of this analysis. The chemical composition, performed on a sample of the P2 failed stainless steel blade, was analyzed by optical emission spectroscopy (OES), as shown in Table 2. These values followed the proprietary standard except with a little excess of the carbon content.

The chemical composition results found that the material used in the manufacture of the blade was X20CrMo13 type steel, as shown in Table 2.

The presence of inclusions of the oxide and sulfide types are acceptable, according to the manufacturer's quality control standards, see Figure 5. Figure 5A shows inclusions of the globular oxide type (D) thick series of level 1.5, and sulfide type (C) fine series level 1.5, at a region below the fracture surface of the $\mathrm{P} 2$ blade, and Figure 5B shows inclusions of the globular oxide type (D) thick series of level $1 / 2$, and sulfide type (C) fine series level 1, at a region of the VB blade base.
A

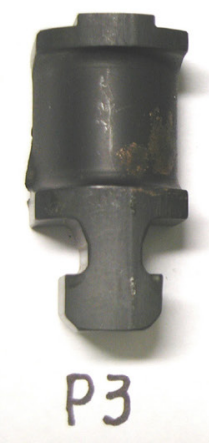

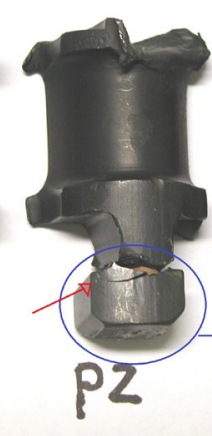

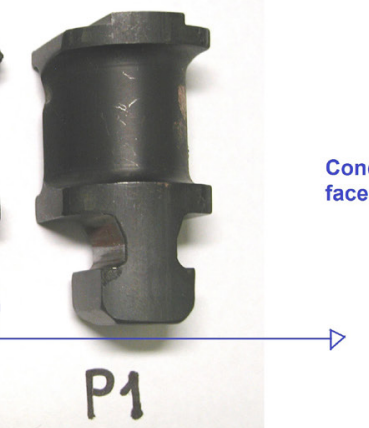

B

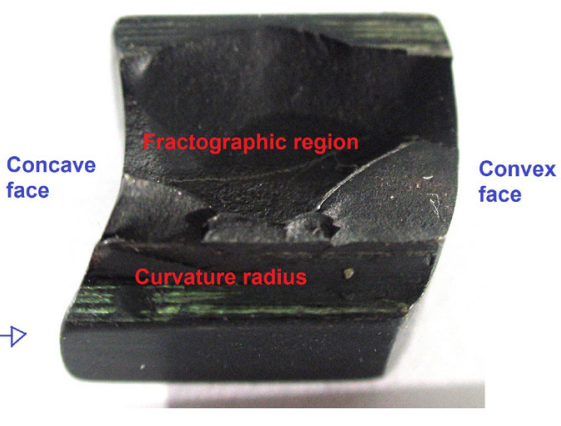

Figure 3. (A) Blades named P1 (adjacent blade), P2 (failed blade), and P3 (adjacent blade). (B) Detail of the fracture surface of the P2 blade base.
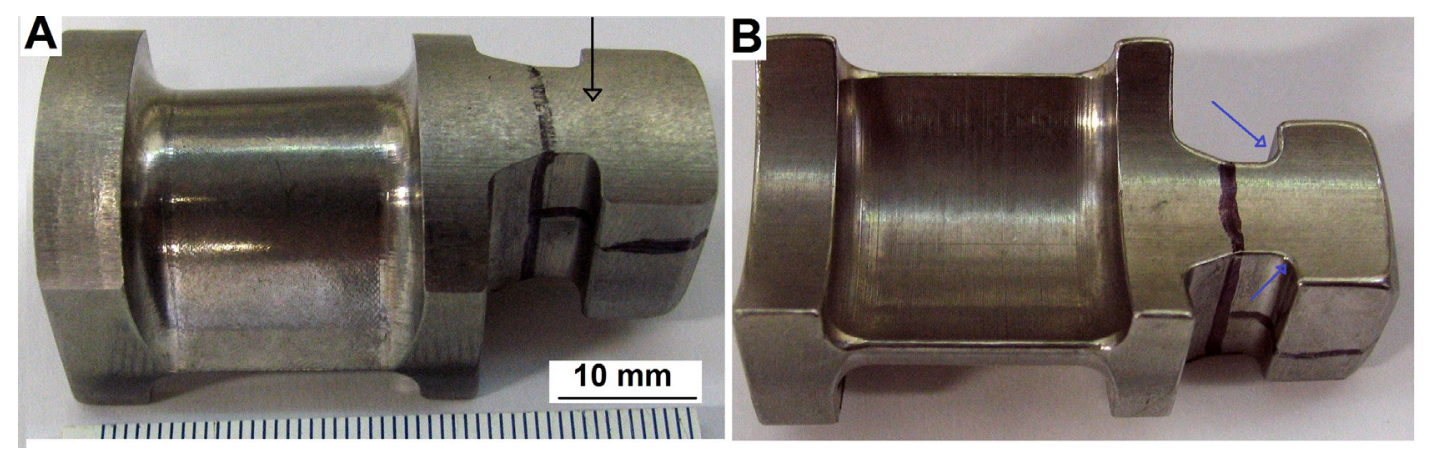

Figure 4. Blade called a virgin blade (VB) without service, seen in the opposite position. (A) The black arrow shows the region in which the metallographic (longitudinal cross-section) analysis was performed. (B) The blue arrow shows a stress concentration region at the blade's base, inherent in the project.

Table 2. Chemical compositions (wt.\%) of the P2 failed X20CrMo13 stainless steel blade and standard proprietary chemical composition (SC), measured by OES.

\begin{tabular}{ccccccccccc}
\hline & $\mathrm{C}$ & $\mathrm{Si}$ & $\mathrm{Mn}$ & $\mathrm{P}$ & $\mathrm{S}$ & $\mathrm{Cr}$ & $\mathrm{Ni}$ & $\mathrm{Mo}$ & $\mathrm{Fe}$ \\
\hline P2 & 0,226 & 0,47 & 0,50 & 0,021 & 0,019 & 12,42 & 0,69 & 1,01 & $\mathrm{Bal}$ \\
\hline SC & $0,17-0,22$ & $1,0($ máx) & 1,0 (máx) & 0,045 (máx) & 0,030 (máx) & $12-14$ & 1,0 (máx) & $0,9-1,3$ & $\mathrm{Bal}$. \\
\hline
\end{tabular}


The microstructure observed is characteristic of a martensitic phase in the annealed condition, as shown in Figure 6.

A typical microstructure of martensitic stainless steel, with spheroidal carbides, is detected in P2 failed blade, as shown in Figure 6A, carbides are precipitated mainly in the grain boundaries. The existence of inclusions of the globular and elongated oxide types, of the sulfide or silicate type, is also observed. This microstructure of spheroidized carbides is coherent with the heat treatment of quenching and tempering applied to the material. Carbides precipitate typically at the grain boundaries, as shown in Figure 6B.
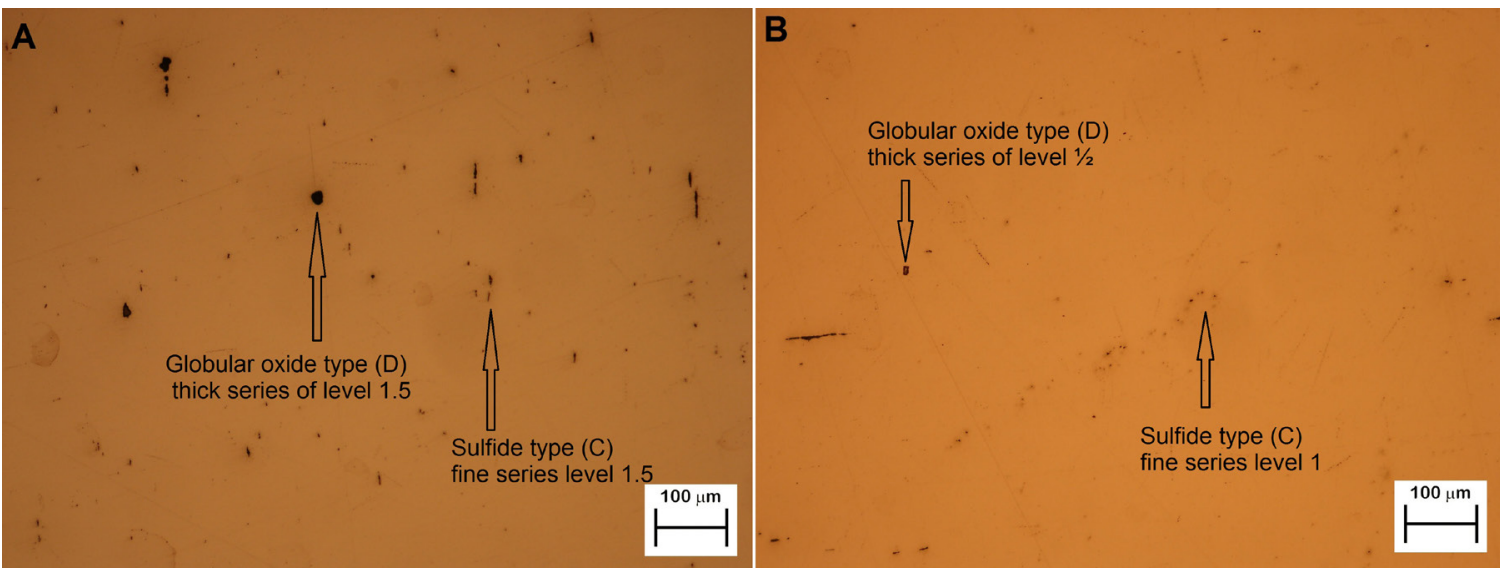

Figure 5. Optical images of unetched cross-sectional surfaces of the X20CrMo13 type steel blades. (A) Inclusions of the globular oxide type (D) thick series of level 1.5, and sulfide type (C) fine series level 1.5, at the fracture surface of the P2 (B) Inclusions of the globular oxide type (D) thick series of level 1/2, and sulfide type (C) fine series level 1, at a region of the VB blade base.
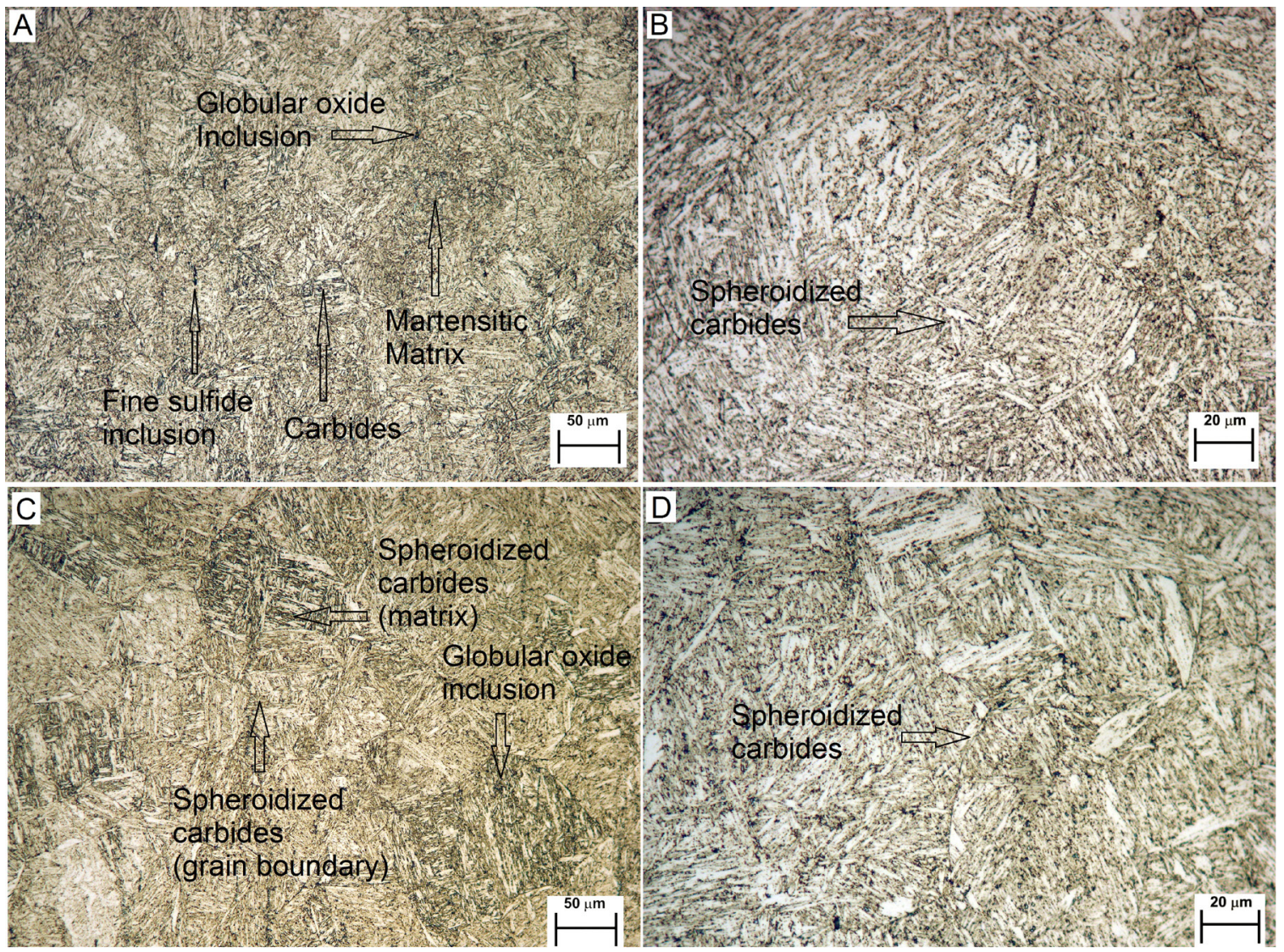

Figure 6. Optical images of etched cross-sectional surfaces of the X20CrMo13 type steel blades. (A) The region below the P2 blade's fractured surface. (B) Detail of (A) showing spheroidized carbides precipitated in the grain boundaries. (C) Cross-sectional region at the base of the VB blade (without service). (D) Detail of (C) showing spheroidized carbides precipitated at the grain boundaries (Villela's etchant). 
A photomicrograph of a cross-sectional region at the base of the VB blade (without service) is shown in Figure 6C, presenting a typical microstructure of tempered martensitic stainless steel with the presence of small spheroidal carbides precipitated at the matrix and the grain boundaries. The hightemperature service conditions probably induced carbides growth and made it more significant than in the virgin blade, as shown in Figure 6D.

From the fracture surface analysis, it is possible to evidence the low levels of work loading involved, as shown in Figure 7. There are four different fatigue crack propagation planes shown in Figure 7A, plane 1 (bottom), planes 2, 3, and 4 (top). Figure $7 \mathrm{~B}$ shows the principal crack plane (plane 1), secondary cracks (yellow arrow), and plastic deformation marks located in the curvature radius of the blade top base, typical of the wear process called fretting. The fretting process only occurs when two surfaces in contacts are mechanically loaded and undergo relative movements of low amplitude ${ }^{12}$. Secondary cracks were activated during the final blade fracture stage ${ }^{21}$, as shown in Fig 8A. The fatigue crack propagation that caused the $\mathrm{P} 2$ blade failure is shown in Figure 8B, where progression lines are observed that characterize the leading crack nucleation site and the plastic deformation marks caused by fretting.

The non-failed blade P1, located adjacent to the failed blade P2, showed the existence of shiny areas, probably due to the friction of the parts that removed the oxide layer, and plastically deformed material, characteristic of fretting, developed at the edge of the convex face, as shown in Figure 9A. At sharp plastic deformation of the material occurred, it is also detected the origin of a crack at the edge between the radius of curvature and the blade's concave face, as shown in Figure 9B, nucleated and propagated by fretting fatigue mechanism ${ }^{14}$.

In comparison with the fractographic images shown in Figure 7 and Figure 8, one concluded that the crack nucleation in the P1 blade occurred at the same position as the leading crack that caused the total collapse of the P2
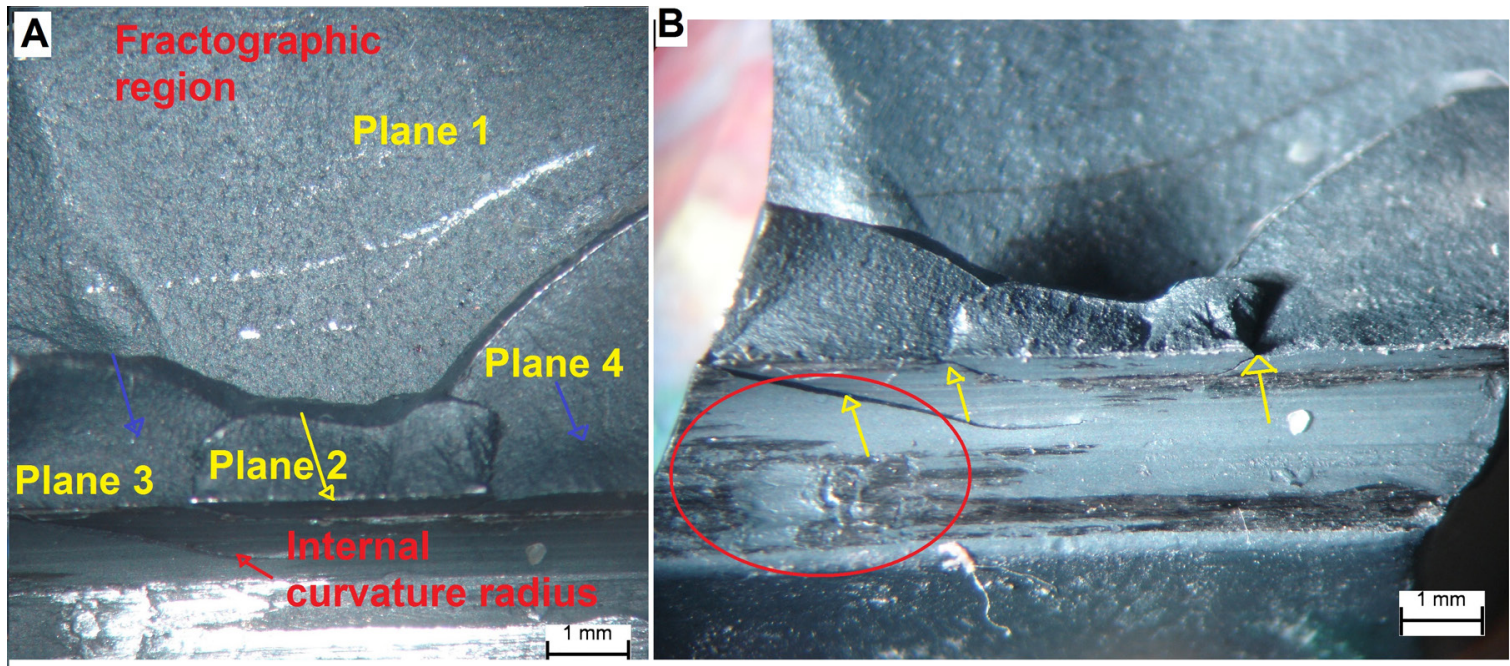

Figure 7. Stereographic images of the fracture surface of the P2 blade. (A)The crack nucleation sites (yellow arrow). There are four different fatigue crack propagation planes, plane 1 (bottom), planes 2, 3, and 4 (top). (B) Detail of (A) observed by another angle.
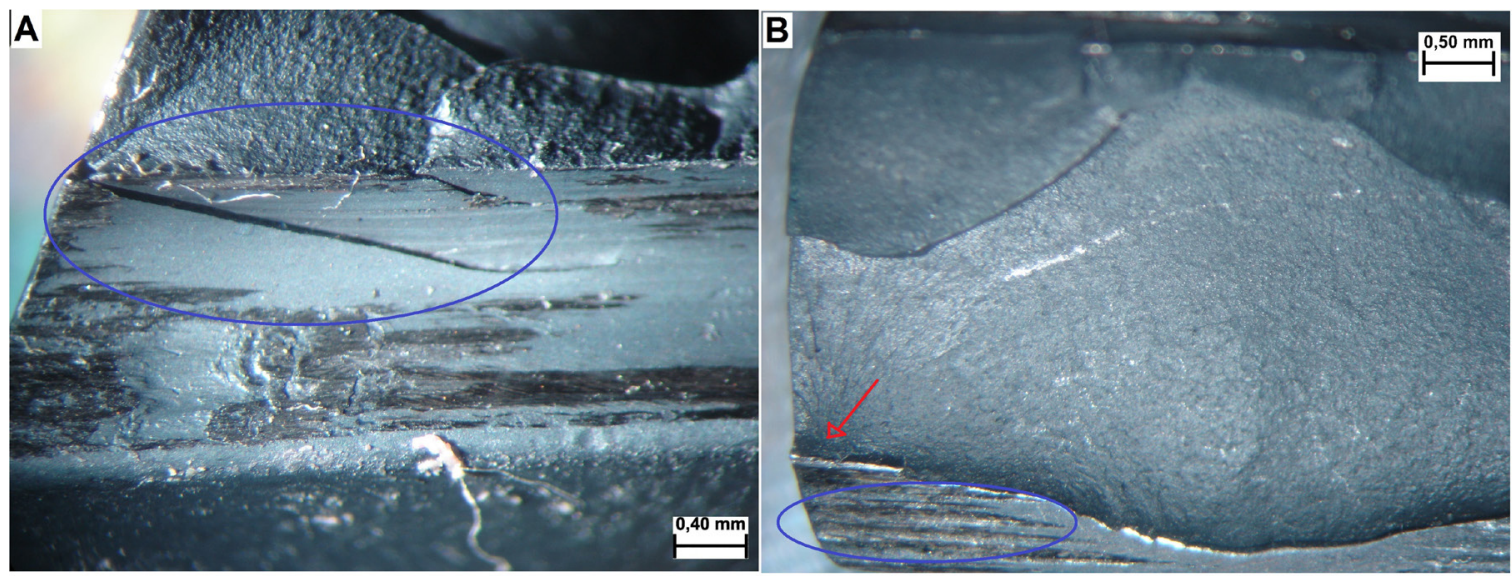

Figure 8. Stereographic images of the fracture surface of the P2 blade. (A) Detail with higher magnification of the region shown in Figure 7. (B) Detail of the principal plane (plane 1) of fatigue crack propagation. 
blade, that is, at the edge between the radius of curvature and the concave face of the blade, as shown in Figure 10A. The crack propagated towards the part interior in which the outer face has many scratches from the machining process, as shown in Figure 10B. (yellow arrows). It is also possible to visualize, near the crack nucleation site, the debris of oxidized material, which was generated during fretting 4 . On the concave face, see Figure 10B, where a curvature radius of approximately $1.2 \mathrm{~mm}$ has been simulated (part design) where it is possible to observe an error in the
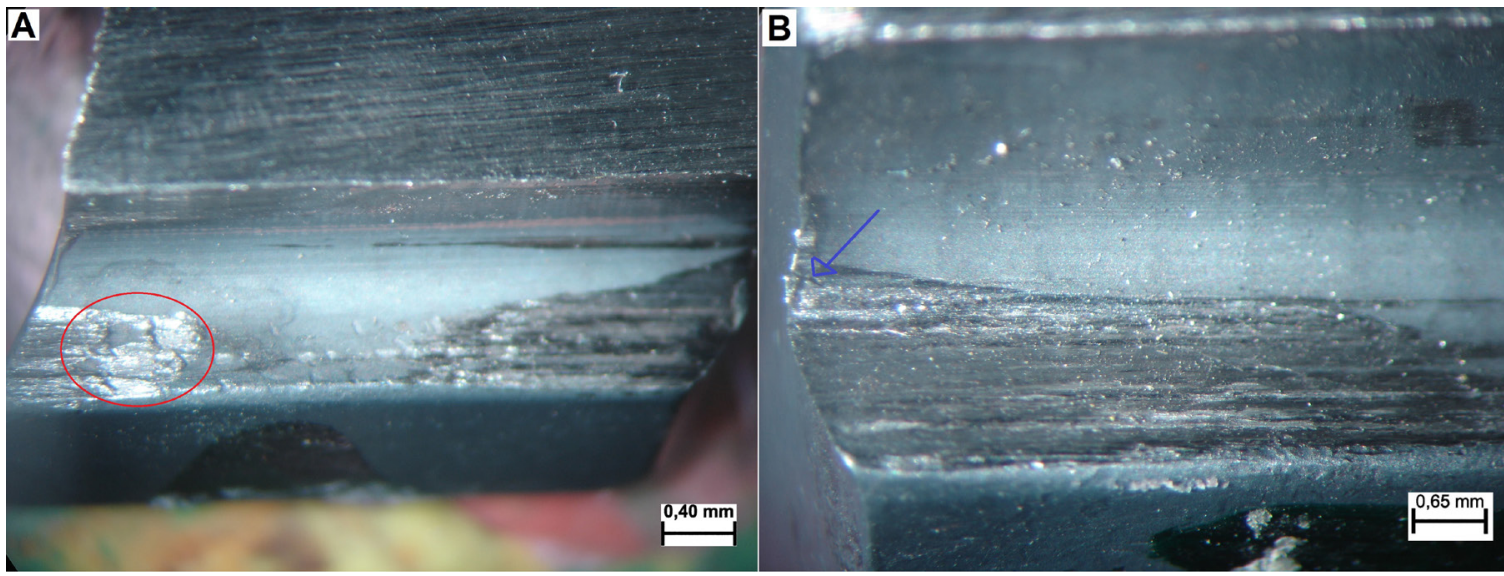

Figure 9. Stereographic images of the non-failed blade P1. (A) Showing shiny areas and plastically deformed material (red ellipse). (B) Plastic deformation at the origin of a crack at the edge between the curvature radius and the concave face of the blade (blue arrow).
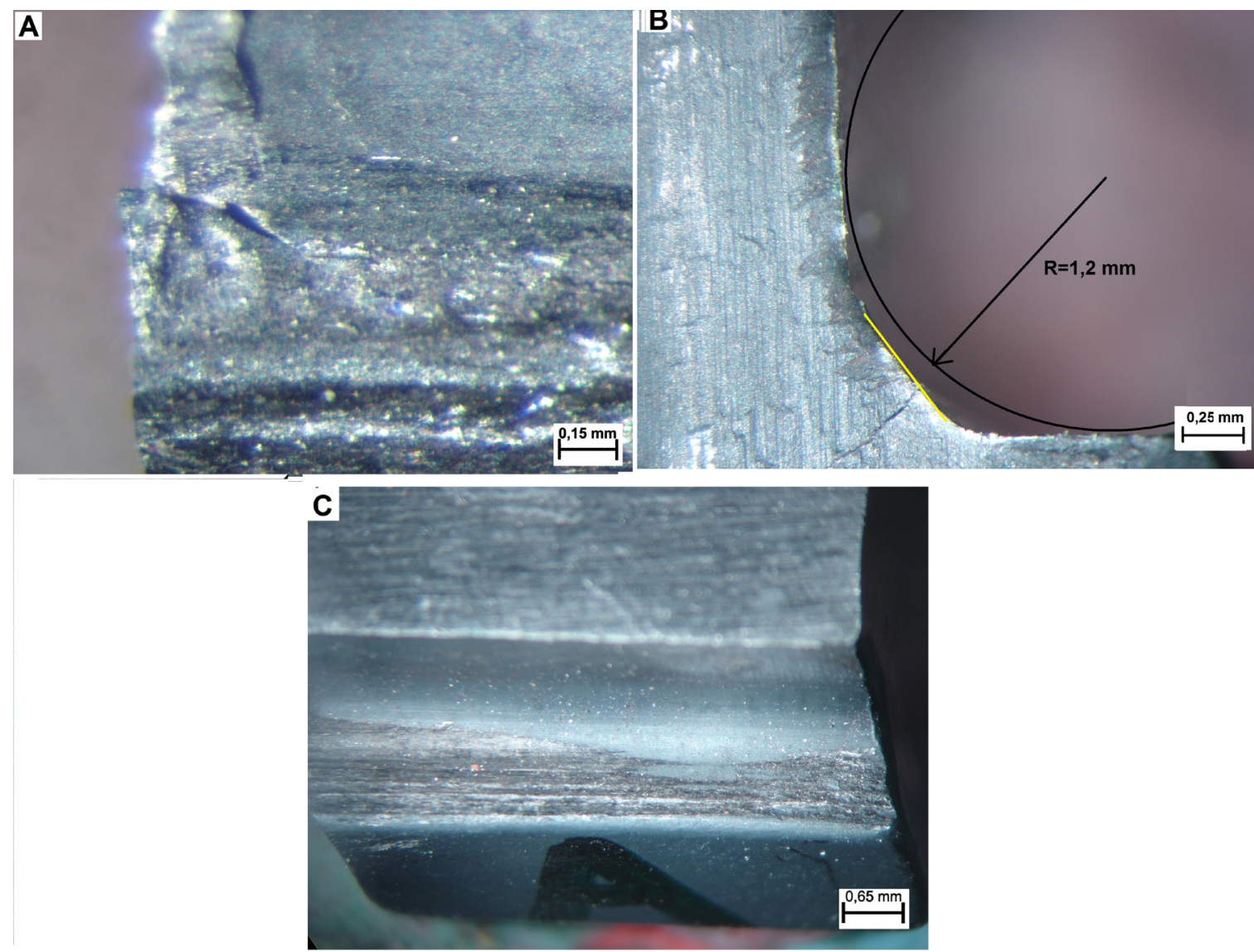

Figure 10. (A) Detail with higher magnification of the region shown in Figure 7. (B) The concave face view (yellow lines) of Figure 10B, where a curvature radius of approximately $1.2 \mathrm{~mm}$ has been simulated (part design, stress raiser level (yellow line). (D) Curvature radius stereography at the base of the P3 blade. 


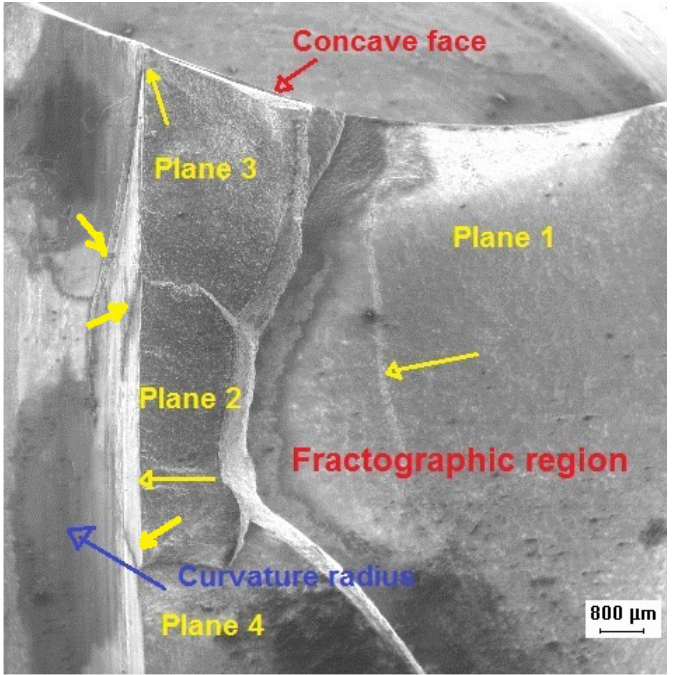

Figure 11. SEM images showing the fracture surface of the P2 blade.

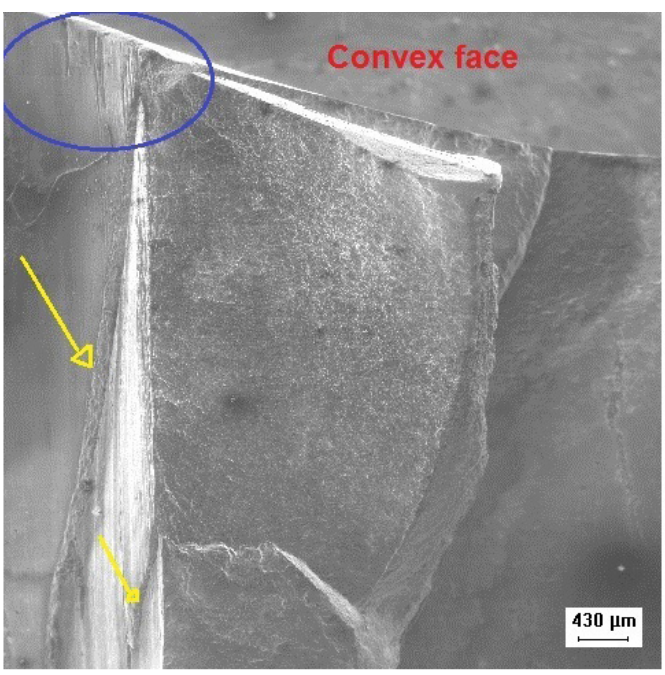

Figure 12. SEM images of the fracture surface of the P2 blade. machining of the curvature radius, causing in addition to the stress raiser a level (yellow line) which, after mounting on the rotor, increases the contact force between the parts, facilitating the nucleation of cracks by fretting. The same fretting fatigue damage structures detected in P1 and P2 blades were also observed at the base of the P3 blade, see Figure 10C.

From the SEM images are shown in Figure 11, one observes the occurrence of secondary cracks located in the radius of curvature of the coupling with the rotor, the convex face of the blade, and the four fracture planes, named in this work as principal plane 1 and secondary planes 2, 3 and 4. From the analysis of the crack progression lines, the crack nucleation sites were detected, one concludes that this nucleation occurred due to fretting. Figure 11 shows a secondary crack site starting from the radius of curvature and propagating across the blade changing orientation (plane) due to the change in the balance of loads. Note the existence of secondary cracks, located in the region of the radius of curvature of the failed blade base.

In the same part P2, Figure 12 shows numerous typical shear scratches between metals due to plastic deformation, tears, entrainment, and secondary cracks. It is possible to observe dragging and tearing material between the convex region and the curvature radius of the P2 blade, as shown in Figure 12. These damages occur when two metallic surfaces are placed in contact, under mechanical loading, and suffer sliding at low amplitudes and high frequencies.

By analyzing a fractured surface of the P2 plane showing two crack propagation planes, as shown in Figure 11, and the fracture progression lines, it was possible to locate the leading crack's nucleation site, as shown in Fig 13A and Figure 13B. Debris generated by fretting ${ }^{7}$ was found near the leading crack nucleation site of the P2 blade, as shown in Figure 14. Localized material loss and plastically deformed areas were observed in the P1 blade, as shown in Figure 15A, and crack as shown
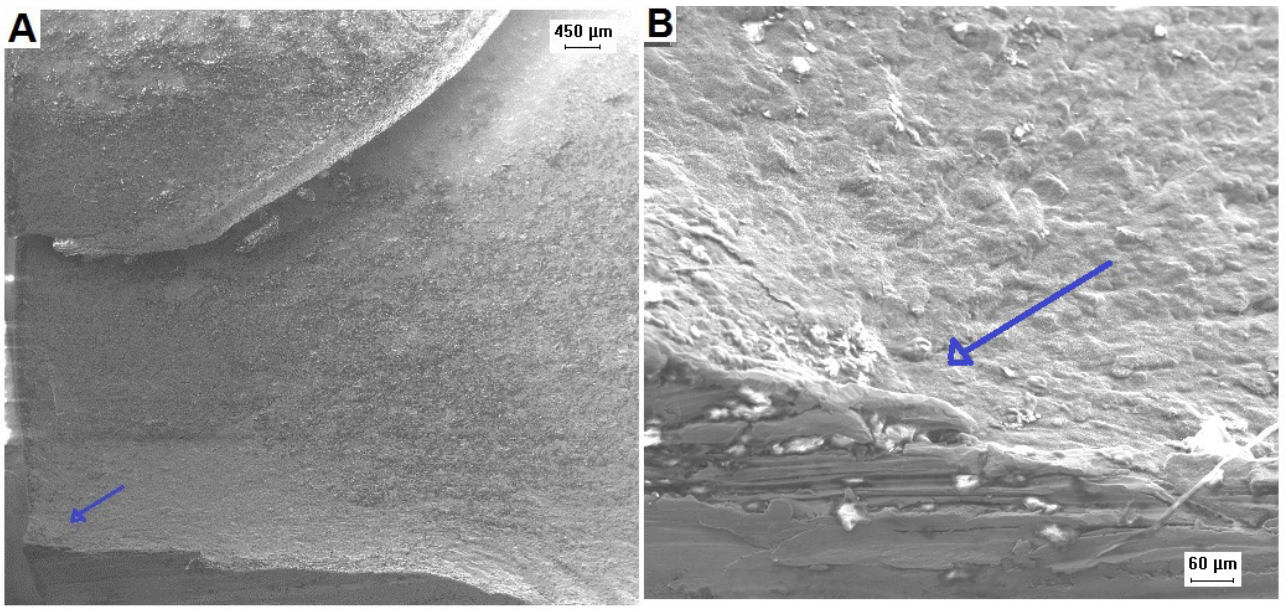

Figure 13. SEM images of the fracture surface of the P2 blade. (A) Crack propagation planes, as shown in Figure 11A, and the fracture progression lines, it was possible to locate the nucleation site of the main crack (blue arrow). (B) Detail of previous image evidencing the crack origin. 


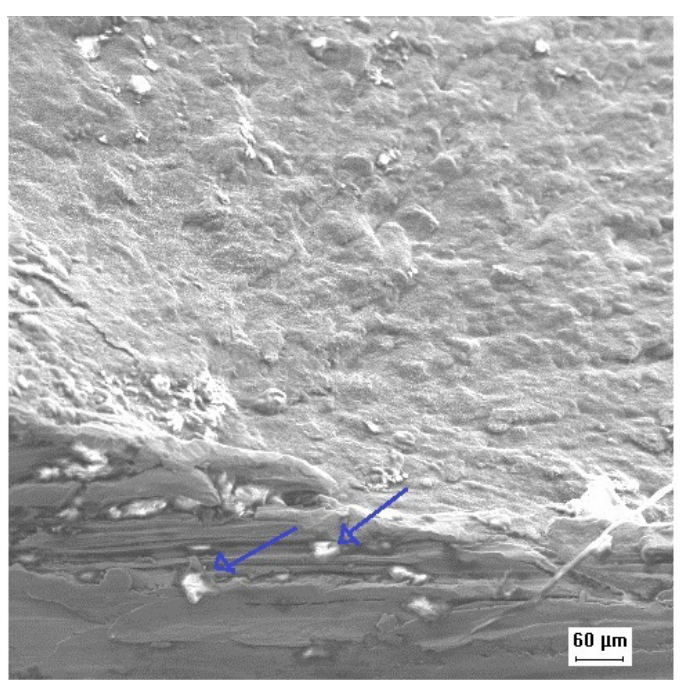

Figure 14. SEM images of the fracture surface of the P2 blade. Showing debris generated by fretting (blue arrows) located near the leading crack nucleation site.

in Figure 15B and Figure 15C, corroborating fretting fatigue in the system.

According to information obtained by the manufacturer, the hardness should vary between 220 to $240 \mathrm{HB}$. The average hardness results were slightly above the specified, as shown in Table 3 . The hardness results were slightly higher than specified, which could result from a poorly done tempering treatment. The increase in hardness reduces the toughness of the material, allowing the crack propagation.

Table 3. Brinell hardness results X20CrMo13 stainless steel P1 blade.

\begin{tabular}{cc}
\hline Indentation & Hardness $\mathrm{HB}\left(\mathrm{P} / \mathrm{D}^{\wedge} 2=30\right)$ \\
\hline 01 & 244 \\
\hline 02 & 249 \\
\hline 03 & 249 \\
\hline 04 & 255 \\
\hline 05 & 255 \\
\hline Average & $\mathbf{2 5 0 , 4}$ \\
\hline Standard dev. & $\mathbf{4 , 7}$
\end{tabular}
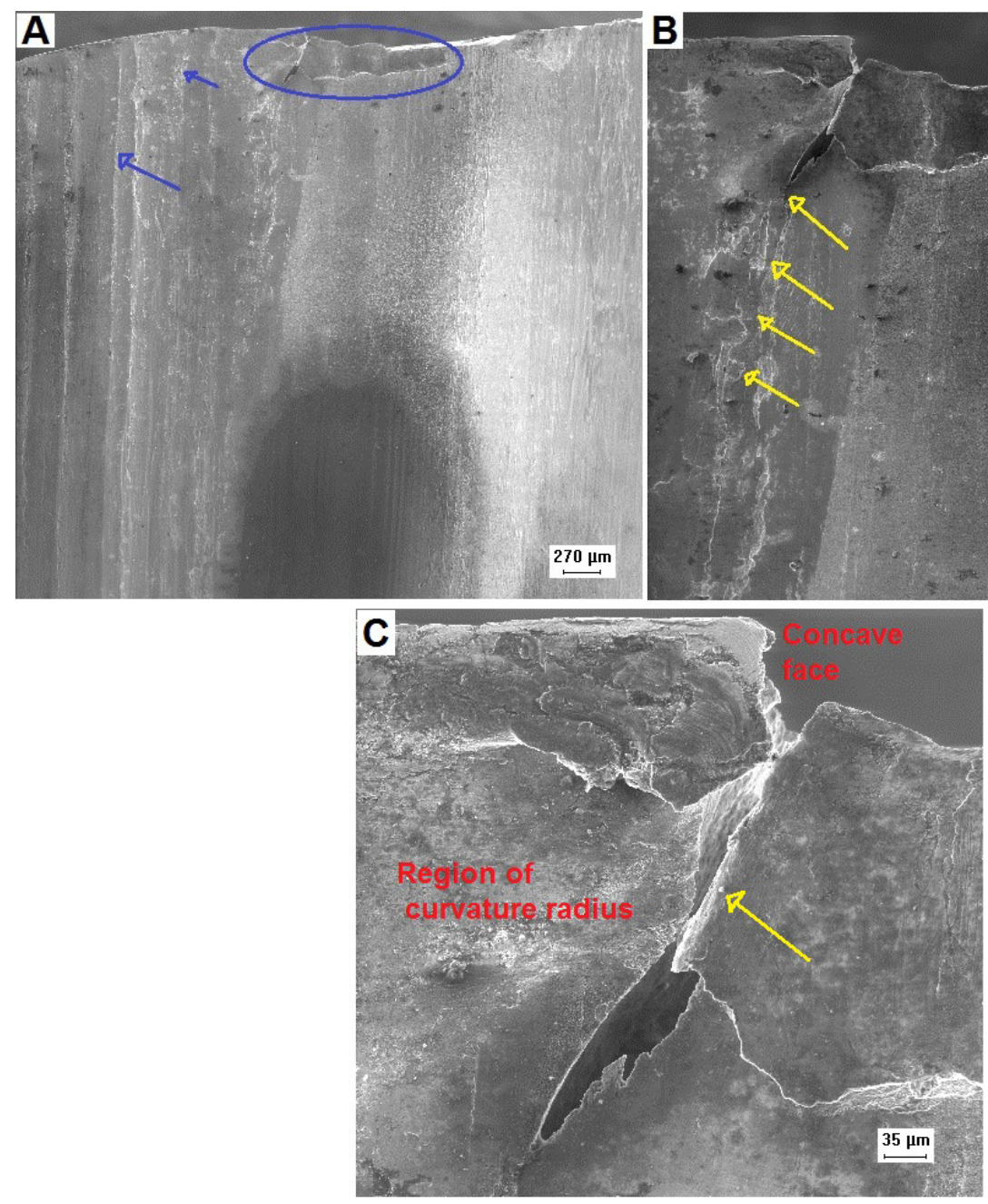

Figure 15. SEM images of the fracture surface of the P1 blade. (A) Localized material loss (blue ellipse) and plastically deformed areas (green arrow). (B) Fretting fatigue crack (yellow arrows). (C) Higher magnification of the previous image evidencing the fretting fatigue crack (yellow arrow). 


\section{Conclusions}

The results of chemical analysis and hardness testing, along with a microstructural characterization, confirmed that the blades' material was following the manufacturer's specifications, indicating that the material did not cause the unexpected failure of the blades.

Fractographic indicated that fatigue cracks were nucleated on the shear scratches, which were present on the base of P2 blade right on the coupling with the rotor. Sequential fractographic examination on the base blade base surface revealed the presence of superficial deformation and secondary cracks, which eventually lead to material detachment and wear groove (shear scratches) formation.

The crack that caused the P2 blade failure was initiated by fretting, due to low amplitude oscillatory movement in the region of the blade base and rotor coupling of the turbine. Its propagation occurred due to the phenomenon of fatigue. The occurrences were strongly evidenced by the location, in the region of the crack nucleation sites, of debris originating from worn-out material and the plastic deformations that are striking characteristics of the existence of the wear mechanism that operates during fretting.

\section{Recommendations}

a) Study the possibility of eliminating the relative movement in the blade/rotor coupling, thus avoiding the possibility of low amplitude oscillations causing the crack nucleation process known as fretting.

b) Improve the process of machining the base blade curvature radius, a place conducive to the nucleation of cracks by fretting.

c) During the blade assembly operation, care must be taken not to introduce mechanical damage to the blade base, as this is a favorable region for the propagation of damage by the fatigue mechanism.

d) Increase the roughness in the region of coupling the blade base with the turbine rotor, employing shot blasting surface treatment, because scientific works prove that rough surfaces are less conducive to suffering fretting damage. In addition to increasing the surface roughness, this treatment has the advantage of introducing residual compressive stresses on the surface, which cause a considerable delay effect in the crack nucleation process by the fatigue mechanism.

\section{Acknowledgments}

The authors would like to thank Prof. Dr. Dirceu Spinelli, in memoriam, for inspiration and dedication to work throughout his life.

\section{References}

1. Sameezadeh M, Hasanlou S, Zafari H, Vaseghi M. Numerical simulation and experimental investigation on a steam turbine blade fractured from the lacing hole. Eng Fail Anal. 2020;117:1 11.

2. Schijve J. Fatigue of structures and materials. 2nd ed. USA: Springer; 2009.

3. Bhagi LKV, Rastogi V, Gupta P. A brief review on failure of turbine blades. In: STME-2013 Smart Technologies for Mechanical Engineering; 2013; New Delhi. Proceedings. New Delhi: Delhi Technological University; 2013.

4. Mousavinia M, Bahrami A, Rafiaei SM, Rajabinejad M, Taghian M, Seyedi SJ. Root cause analysis of failure of bolts in the low pressure section of a gas turbine in an oil and gas production plant. Eng Fail Anal. 2020;115:104675.

5. Rivaz A, Mousavi Anijdan SH, Moazami-Goudarzi M. Failure analysis and damage causes of a steam turbine blade of 410 martensitic stainless steel after 165,000 h of working. Eng Fail Anal. 2020;113:104557.

6. Bahrami A, Mousavi Anijdan SH, Taheri P, Yazdan Mehr M. Failure of AISI 304H stainless steel elbows in a heat exchanger. Eng Fail Anal. 2018;90:397-403.

7. Szolwinski MP, Farris TN. Mechanics of fretting fatigue crack formation. Wear. 1996;198:93-107.

8. Berthier Y, Vincent L, Godet M. Fretting fatigue and fretting wear. Tribol Int. 1989;22(4):235-42.

9. Bahramia A, Mousavi Anijdana SH, Golozarb MA, Shamanianb M, Varahrama N. Effects of conventional heat treatment on wear resistance of AISI H13 tool steel. Wear. 2005;258(56):846-51.

10. Aghaie-Khafri M, Mousavi Anijdan SH, Amirkamali M. Microstructural evolution under ausforming and aging conditions in 17-4 PH stainless steel. Mater Res Express. 2019;6(10):106532.

11. Vardar N, Ekerim A. Failure analysis of gas turbine blades in a thermal power plant. Eng Fail Anal. 2007;14:743-9.

12. Bhatti NA, Wahab MA. Fretting fatigue crack nucleation: a review. Tribol Int. 2018;121:121-38.

13. Hutson A, Nicholas T, John R. Fretting fatigue crack analysis in Ti-6Al-4V. Int J Fatigue. 2005;2-7(10-12):1582-9.

14. Nicholas T. High cycle fatigue: a mechanics of materials perspective. 6th ed. USA: Elsevier; 2006. p. 261-321.

15. Sun S, Li L, He K, Yue Z, Yang W, Yu Z. Fretting fatigue damage mechanism of Nickel-based single crystal superalloys at high temperature. Int J Mech Sci. 2020;186:105894.

16. Xue F, Wang Z-X, Zhao W-S, Zhang X-L, Qu B-P, We L. Fretting fatigue crack analysis of the turbine blade from nuclear power plant. Eng Fail Anal. 2014;44:299-305.

17. Ziegler D, Puccinelli M, Bergallo B, Picasso A. Investigation of turbine blade failure in a thermal power plant. Case Stud Eng Fail Anal. 2013;1:192-9.

18. ASM International. ASM handbook. Vol. 1. Metals Park, OH: ASM International: 1993.

19. ASMT International. ASTM E3-11(2017). Standard Guide for Preparation of Metallographic Specimens. West Conshohocken, PA: ASTM International; 2017.

20. ASMT International. ASTM E45-18a. Standard test methods for determining the inclusion content of steel. West Conshohocken, PA: ASTM International; 2017.

21. Kong Y, Bennett CJ, Hyde CJ. A review of non-destructive testing techniques for the in-situ investigation of fretting fatigue cracks. Mater Des. 2020;196:109093. 